\title{
The DEA and Intuitionistic Fuzzy TOPSIS Approach to Departments' Performances: A Pilot Study
}

\author{
Babak Daneshvar Rouyendegh \\ Department of Industrial Engineering, Atılım University, P.O. Box 06836, Incek, Ankara, Turkey \\ Correspondence should be addressed to Babak Daneshvar Rouyendegh, babekd@atilim.edu.tr
}

Received 7 August 2011; Accepted 5 October 2011

Academic Editor: Hui-Shen Shen

Copyright (C) 2011 Babak Daneshvar Rouyendegh. This is an open access article distributed under the Creative Commons Attribution License, which permits unrestricted use, distribution, and reproduction in any medium, provided the original work is properly cited.

This paper processes a unification of Fuzzy TOPSIS and Data Envelopment Analysis (DEA) to select the units with most efficiency. This research is a two-stage model designed to fully rank the organizational alternatives, where each alternative has multiple inputs and outputs. First, the alternative evaluation problem is formulated by Data Envelopment Analysis (DEA) and separately formulates each pair of units. In the second stage, we use the opinion of experts to be applied into a model of group Decision-Making (DM) called the Intuitionistic Fuzzy TOPSIS (IFT) method. The results of both methods are then multiplied to obtain the results. DEA and Intuitionistic Fuzzy TOPSIS ranking do not replace the DEA classification model; rather, it furthers the analysis by providing full ranking in the DEA context for all units by aggregate individual opinions of decision makers for rating the importance of criteria and alternatives.

\section{Introduction}

Data Envelopment Analysis (DEA) measuring the relative efficiency of peer decision-making units (DMUs) with multiple inputs and multiple outputs was introduced by Charnes et al. [1]. This method is based on linear programming (LP), which gives it the ability to measure the decision units in a relative manner, though it has difficulties in measuring different scales and more than one scale, as well as in comparing entries or outputs that are in different units. Multi-Criteria Decision-Making (MCDM) is a modeling and methodological tool for dealing with complex engineering problem. However, the MCDM literature was entirely separate from DEA research until 1988, when Golany combined interactive, multiple-objective linear programming and DEA. Whilst the MCDM literature does not consider a complete ranking as their ultimate aim, they do discuss the use of preference information to further refine the discriminatory power of the DEA models. In this manner, the decision-makers could specify which inputs and outputs should lend greater importance to the model solution. 
However, this could also be considered the weakness of this method, since additional knowledge on the part of the decision-makers is required. Golany [2], Kornbluth [3], Golany and Roll [4], and Halme et al. [5] each incorporated preferential information into the DEA models through, for example, a selection of preferred input/output targets or hypothetical DMUs. A separate set of papers reflected preferential information through limitations on the values of the weights, which can almost guarantee a complete DMU ranking [6].

DEA has been applied to DMUs in various forms, such as hospitals, cities, universities, business firms, and many others [7]. During the last decade, there have been attempts to fully rank units in the context of DEA. Cook and Kress [8], Cook et al. [9], and Green et al. [10] used subjective decision analysis. Norman and Stoker [11] asserted a step-by-step approach that uses the selected simple ratios between input and output couples. Ganley and Cubbin [12] improved the common weights, which maximizes the efficiency rates for all units. Sinuany-Stern et al. [13] ordered all units by using linear discriminated analysis that is based on the given DEA dichotomic classification. Friedman and Sinuany-Stern [14] used canonical correlation analysis (CCA/DEA) to order the units that are fundamental in common weights. Friedman and Sinuany-Stern [15] developed the discriminate analysis of ratios instead of traditional linear discriminate analysis. Also (DR/DEA) Oral et al. [16] used the cross-efficiency matrix for choosing $\mathrm{R}$ and $\mathrm{D}$ projects. There are deficiencies in all methods related to the nature of the methods themselves. Some of the deficiencies occur due to human faults, and some occur due to the presence of a large number of options.

Data Envelopment Analysis (DEA) as a popular method has been extensively used for ranking and classifying the decision-making units. DEA, a nonparametric technique, is an alternative to multivariate statistical methods when it is used for the data with multiple inputs and outputs. DEA provides researchers a wide usage opportunity since it does not need any assumptions, unlike the multivariate statistical methods, and it has a flexibility to add new restrictions to model according to researchers need.

The DEA is a method for mathematically comparing difference in DMUs' productivity based on multiple inputs and outputs. The ratio of weighted inputs and outputs produces a single measure of productivity called relative efficiency. The DMUs that have a ratio of 1 are referred to as "efficient", given the required inputs and produced outputs. The units that have a ratio less than 1 are "less efficient" relative to the most efficient units. Because the weights for the input and the output variables of DMU's are computed to maximize the ratio and then compared to a similar ratio of the best-performing DMU's, the measured productivity is also referred to as "relative efficiency" [17].

Intuitionistic fuzzy set (IFS) introduced by Atanassov [18] is an extension of the classical fuzzy set (FS), which is a suitable way to deal with vagueness. Intuitionistic fuzzy sets have been applied many areas such as medical diagnosis [19-21], decision-making problems [22-31], pattern recognition [32-37], supplier selection [38], personel selection [39], facility location selection [40], and evaluation of renewable energy [41].

The rest of the paper is organized as follows: Section 2 describes the literature review, Section 3 explains the materials and methods, Section 4 Applying the methodology: an Illustrative Problem, and finally Sections 4 and 5 contain discussion and conclusion.

\section{Literature Review}

DEA is a nonparametric approach that does not require any assumptions about the functional form of the production function. About 1000 articles have been written on the subject, providing numerous examples and further development of the model. In the simplest case 
of a unit having a single input and output, efficiency is defined as the ratio of output/input. DEA deals with units having multiple inputs and outputs that can be incorporated into an efficiency measure where the weighted sum of outputs is divided by the weighted sum of inputs [14].

The application of DEA to universities has generally focused on the efficiencies of university programs departments. The studies are by A. Bessent and W. Bessent [42], Tomkines and Green [43], Beasley [44], J. Johnes and G. Johnes [45], Sinuany-Stern et al [46], Leitner et al. [47], and Rayeni et al. [48].

A. Bessent and W. Bessent [42] used DEA in measuring the relative efficiency of education programs in a community college. Educational programs (DMUs) were assessed on such that outputs are revenue from state government, number of students completing a program, and employer satisfaction with training of students. These outputs represented significant planning objectives. Inputs included student contact hours, number of full-time equivalent instructors, square feet of facilities for each program, and direct instructional expenditures. The authors demonstrated how DEA can be used in improving program, terminating programs, initiating new programs, or discontinuing inefficient program.

Tomkins and Green [43] studied the overall efficiency of university accounting departments. They ran a series of six efficiency models of varying complexity where staff numbers were an input and student numbers an output. Results indicated that different configurations of multiple incommensurate inputs and outputs produced substantially stable efficiency score. On the other hand, Beasley studied chemistry and physics departments on productive efficiency where financial variables such as research income and expenditure were treated as inputs. Outputs consisted of undergraduate and postgraduate student numbers as well as research rating. İn a follow-up study, Beasley analyzed the same data set in an effort to determine the research and teaching efficiencies jointly, where weight restrictions were used.

J. Johnes and G. Johnes [45] explored various models in measuring the technical efficiency of economics department in terms of research outputs. They discuss the potential problems in choosing inputs and outputs. The authors also provide a good guide to interpreting efficiency scores. İt is interesting to note that both Beasley [44] and Johnes list research income as an input.

Sinuany-Stern et al. [46] examined the relative efficiency of 21 academic departments in Ben-Gurion University. Operating costs and salaries were entered as inputs, while grants, publications, graduate students, and contact hours comprised the outputs. Analysis suggested that the operating costs could be reduced in 10 departments. Furthermore, the authors tested for the sensitivity of efficiency score to deleting or combining variables. Their finding indicated that efficient departments may be rerated as inefficient as a result of changing the variable mix.

Leitner et al. [47] examined the measure efficiency in the university sector, as well as to apply DEA in the frame of Austrian university. DEA exceeds traditional methods analyzing university activities using simple ratio calculations. On the one hand, it determines the performance efficiency of university departments; on the other hand, it goes beyond this task and shows the improvement potential for each evaluated unit separately.

Rayeni et al. [48] explored the evolution of productivity of the university departments operating in the Islamic Azad University Zahedan Unit's education departments for the period between 2004 and 2009. Since the Islamic Azad University Zahedan Unit's education departments are part of the public sector where economic behavior is uncertain and there is no price information on the services produced, the Malmquist index based on DEA approach is well suited for productivity measurement where staff numbers (professors, assistant 
professor, lecture, and educational expert), number of registered student in the term of the academic year, number of presented units in each department by gust lectures were an input and number of graduates in the academic year, number of student passing to higher level, and research (books, published article or presented in authentic conferences and report and research projects) an output.

\section{Materials and Methods}

DEA deals with classifying the units into two categories, efficient and inefficient, based on two sets of multiple outputs contributing positively to the overall evaluation $[12,19]$. The original DEA does not perform full ranking; it merely provides classification into two dichotomic groups: efficient and inefficient. It does not rank them; all efficient units are equally good in the pareto sense.

In this study, our model integrates two well-known models, DEA and Intuitionistic Fuzzy TOPSIS. The priorities obtained from DEA and Intuitionistic Fuzzy TOPSIS method are defined as a ten-step approach. The procedure for DEA and Intuitionistic Fuzzy TOPSIS ranking model has been given as follows.

Step 1. In the first step, determine the result of $e_{k}$ from DEA method.

Measurement of the efficiency for a particular DMU is defined as the ratio of weighted sum of its output to weighted sum of its input. It is also defined as efficiency score of the DMU. For instance, the DMUs are used for the production of $x_{i j}$ inputs and $y_{r j}$ of outputs. $X(t \times n)$ and $Y(m \times n)$ are the amounts of the inputs and outputs, respectively.

\subsection{Mathematical (Weighted Linear) Representation of the Problem}

$$
e_{k}=\max \sum_{r=1}^{t} u_{r} y_{r j}
$$

subject to

$$
\begin{gathered}
\sum_{i=1}^{m} v_{i} x_{i k}=1, \\
\sum_{r=1}^{t} u_{r} y_{r j}-\sum_{i=1}^{m} v_{i} x_{i j} \leq 0, \\
u_{r} \geq 0, \quad r=1, \ldots, t \\
v_{i} \geq 0, \quad i=1, \ldots, m
\end{gathered}
$$

where $e_{k}=$ efficiency score for DMU, $y_{r j}=$ amount of input $r$ for DMU $j, x_{i j}=$ amount of input $i$ for DMU $j, u_{r}=$ weight attached to output $r$ and $v_{i}=$ weight attached to input $i, n=$ number of DMUs, $t=$ number of outputs, and $m=$ number of inputs.

Step 2. Determine the weights of decision makers. 
The IFT method, proposed by Boran et al. [38], is a suitable way to deal with MCDM problem in intuitionistic fuzzy environment. Assume that decision group contains $l$ decision makers. The importance of the decision makers is considered as linguistic terms expressed in intuitionistic fuzzy numbers. Let $D_{k}=\left[\mu_{k}, v_{k}, \pi_{k}\right]$ be an intuitionistic fuzzy number for rating of $k$ th decision maker. Then the weight of $k$ th decision maker can be obtained as

$$
\lambda_{k}=\frac{\left(\mu_{k}+\pi_{k}\left(\mu_{k} /\left(\mu_{k}+v_{k}\right)\right)\right)}{\sum_{k=1}^{l}\left(\mu_{k}+\pi_{k}\left(\mu_{k} /\left(\mu_{k}+v_{k}\right)\right)\right)}, \quad \sum_{k=1}^{l} \lambda_{k}=1
$$

Step 3. Construct aggregated intuitionistic fuzzy decision matrix based on the opinions of decision makers.

Let $R^{(k)}=\left(r_{i j}^{(k)}\right)_{m \times n}$ be an intuitionistic fuzzy decision matrix of each decision maker. $\lambda=\left\{\lambda_{1}, \lambda_{2}, \lambda_{3}, \ldots, \lambda_{l}\right\}$ is the weight of decision maker and $\lambda_{k} \in[0,1]$. In group decision-making process, all the individual decision opinions need to be fused into a group opinion to construct aggregated intuitionistic fuzzy decision matrix. In order to do that, IFWA operator proposed by $\mathrm{Xu}[49]$ is used. $R=\left(r_{i j}\right)_{m \times n}$, where

$$
\begin{aligned}
r_{i j} & =\operatorname{IFW} A_{\curlywedge}\left(r_{i j}{ }^{(1)}, r_{i j}{ }^{(2)}, \ldots, r_{i j}{ }^{(l)}\right) \\
& =\lambda_{1} r_{i j}{ }^{(1)} \oplus \lambda_{2} r_{i j}{ }^{(2)} \oplus \lambda_{3} r_{i j}{ }^{(3)} \oplus \cdots \oplus \lambda_{l} r_{i j}{ }^{(l)} \\
& =\left[1-\prod_{k=1}^{l}\left(1-\mu_{i j}{ }^{(k)}\right)^{\lambda_{k}}, \prod_{k=1}^{l}\left(v_{i j}{ }^{(k)}\right)^{\lambda_{k}}, \prod_{k=1}^{l}\left(1-\mu_{i j}{ }^{(k)}\right)^{\lambda_{k}}-\prod_{k=1}^{l}\left(v_{i j}{ }^{(k)}\right)^{\lambda_{k}}\right] .
\end{aligned}
$$

The aggregated intuitionistic fuzzy decision matrix is defined as follows:

$$
R=\left[\begin{array}{cccc}
r_{11} & r_{12} & \cdots & r_{1 n} \\
r_{21} & r_{22} & \cdots & r_{2 n} \\
\vdots & \vdots & \ddots & \vdots \\
r_{m 1} & r_{m 1} & r_{m 1} & r_{m n}
\end{array}\right]
$$

Here $r_{i j}=\left(\mu_{i j}, v_{i j}, \pi_{i j}\right)(i=1,2, \ldots, m ; j=1,2, \ldots, n)$ is an element of an aggregated intuitionistic fuzzy decision matrix.

Step 4. Determine the weights of criteria.

All criteria may not be assumed to be of equal importance. $W$ represents a set of grades of importance. In order to obtain $W$, all the individual decision maker opinions for the importance of each criteria need to be fused. Let $w_{j}{ }^{(k)}=\left(\mu_{j}{ }^{(k)}, v_{j}{ }^{(k)}, \pi_{j}{ }^{(k)}\right)$ be an intuitionistic 
fuzzy number assigned to criterion $X_{j}$ by the $k$ th decision maker. Then the weights of the criteria are calculated by using IFWA operator:

$$
\begin{aligned}
w_{j} & =\operatorname{IFW} A_{\curlywedge}\left(w_{j}{ }^{(1)}, w_{j}{ }^{(2)}, \ldots, w_{j}^{(l)}\right) \\
& =\lambda_{1} w_{j}{ }^{(1)} \oplus \lambda_{2} w_{j}{ }^{(2)} \oplus \lambda_{3} w_{j}^{(3)} \oplus \cdots \oplus \lambda_{l} w_{j}{ }^{(l)} \\
& =\left[1-\prod_{k=1}^{l}\left(1-\mu_{j}^{(k)}\right)^{\lambda_{k}}, \prod_{k=1}^{l}\left(v_{j}^{(k)}\right)^{\lambda_{k}}, \prod_{k=1}^{l}\left(1-\mu_{j}{ }^{(k)}\right)^{\lambda_{k}}-\prod_{k=1}^{l}\left(v_{j}{ }^{(k)}\right)^{\lambda_{k}}\right], \\
W & =\left[w_{1}, w_{2}, w_{3}, \ldots, w_{j}\right] \quad \text { Here } w_{j}=\left(\mu_{j}, v_{j}, \pi_{j}\right)(j=1,2, \ldots, n) .
\end{aligned}
$$

Step 5. Construct aggregated weighted intuitionistic fuzzy decision matrix.

After the weights of criteria $(W)$ and the aggregated intuitionistic fuzzy decision matrix are determined, the aggregated weighted intuitionistic fuzzy decision matrix is constructed according to the following definition [18]:

$$
\begin{gathered}
R^{\prime}=R \otimes W=\left(\mu_{i j}^{\prime}, v_{i j}^{\prime}\right)=\left\{\left\langle x, \mu_{i j} \cdot \mu_{j}, v_{i j}+v_{j}-v_{i j} \cdot v_{j}\right\rangle\right\}, \\
\pi_{i j}^{\prime}=1-v_{i j}-v_{j}-\mu_{i j} \cdot \mu_{j}+v_{i j} \cdot v_{j} .
\end{gathered}
$$

Then the aggregated weighted intuitionistic fuzzy decision matrix can be defined as follows:

$$
R^{\prime}=\left[\begin{array}{cccc}
r_{11}^{\prime} & r_{12}^{\prime} & \cdots & r_{1 n}^{\prime} \\
r_{21}^{\prime} & r_{22}^{\prime} & \cdots & r_{2 n}^{\prime} \\
\vdots & \vdots & \ddots & \vdots \\
r_{m 1}^{\prime} & r_{m 1}^{\prime} & r_{m 1}^{\prime} & r_{m n}^{\prime}
\end{array}\right]
$$

Here $r_{i j}^{\prime}=\left(\mu_{i j}^{\prime}, v_{i j}^{\prime}, \pi_{i j}^{\prime}\right)(i=1,2, \ldots, m ; j=1,2, \ldots, n)$ is an element of the aggregated weighted intuitionistic fuzzy decision matrix.

Step 6. Obtain the intuitionistic fuzzy positive-ideal solution and intuitionistic fuzzy negative-ideal solution.

Let $J_{1}$ and $J_{2}$ be benefit criteria and cost criteria, respectively. $A^{*}$ is intuitionistic fuzzy positive-ideal solution and $A^{-}$is intuitionistic fuzzy negative-ideal solution. Then $A^{*}$ and $A^{-}$ are obtained as

$$
\begin{array}{ll}
A^{*}=\left(r_{1}^{\prime *}, r_{2}^{\prime *}, \ldots, r_{n}^{\prime *}\right), \quad r_{j}^{\prime *}=\left(\mu_{j}^{\prime *}, v_{j}^{\prime *}, \pi_{j}^{\prime *}\right), \quad j=1,2, \ldots, n, \\
A^{-}=\left(r_{1}^{\prime}, r_{2}^{\prime}, \ldots, r_{n}^{\prime-}\right), \quad r_{j}^{\prime-}=\left(\mu_{j}^{\prime}, v_{j}^{\prime}, \pi_{j}^{\prime}\right), \quad j=1,2, \ldots, n,
\end{array}
$$


where

$$
\begin{gathered}
\mu_{j}^{\prime *}=\left\{\left(\max _{i}\left\{\mu_{i j}^{\prime}\right\} j \in J_{1}\right),\left(\min _{i}\left\{\mu_{i j}^{\prime}\right\} j \in J_{2}\right)\right\}, \\
v_{j}^{\prime *}=\left\{\left(\min _{i}\left\{v_{i j}^{\prime}\right\} j \in J_{1}\right),\left(\max _{i}\left\{v_{i j}^{\prime}\right\} j \in J_{2}\right)\right\}, \\
\pi_{j}^{\prime *}=\left\{\left(1-\max _{i}\left\{\mu_{i j}^{\prime}\right\}-\min \left\{v_{i j}^{\prime}\right\} j \in J_{1}\right),\left(1-\min _{i}\left\{\mu_{i j}^{\prime}\right\}-\max _{i}\left\{v_{i j}^{\prime}\right\} j \in J_{2}\right)\right\}, \\
\mu_{j}^{\prime-}=\left\{\left(\min _{i}\left\{\mu_{i j}^{\prime}\right\} j \in J_{1}\right),\left(\max _{i}\left\{\mu_{i j}^{\prime}\right\} j \in J_{2}\right)\right\}, \\
v_{j}^{\prime-}=\left\{\left(\max _{i}\left\{v_{i j}^{\prime}\right\} j \in J_{1}\right),\left(\min _{i}\left\{v_{i j}^{\prime}\right\} j \in J_{2}\right)\right\}, \\
\pi_{j}^{\prime-}=\left\{\left(1-\min _{i}\left\{\mu_{i j}^{\prime}\right\}-\max _{i j}\left\{v_{i j}^{\prime}\right\} j \in J_{1}\right),\left(1-\max _{i}\left\{\mu_{i j}^{\prime}\right\}-\min _{i}\left\{v_{i j}^{\prime}\right\} j \in J_{2}\right)\right\} .
\end{gathered}
$$

Step 7. Calculate the separation measures.

Separation between alternatives on intuitionistic fuzzy set, distance measures proposed by Atanassov [50], Szmidt and Kacprzyk [51], and, Grzegorzewski [52] including the generalizations of Hamming distance, Euclidean distance, and their normalized distance measures can be used. After selecting the distance measure, the separation measures, $S_{i}^{*}$ and $S_{i}^{-}$, of each alternative from intuitionistic fuzzy positive-ideal and negative-ideal solutions, are calculated. In this paper, we use normalized Euclidean distance

$$
\begin{aligned}
& S_{i}^{*}=\frac{1}{2} \sum_{j=1}^{n}\left[\left|\mu_{i j}^{\prime}-\mu_{j}^{\prime *}\right|+\left|v_{i j}^{\prime}-v_{j}^{\prime *}\right|+\left|\pi_{i j}^{\prime}-\pi_{j}^{*}\right|\right], \\
& S_{i}^{-}=\frac{1}{2} \sum_{j=1}^{n}\left[\left|\mu_{i j}^{\prime}-\mu_{j}^{\prime}\right|+\left|v_{i j}^{\prime}-v_{j}^{\prime}\right|+\left|\pi_{i j}^{\prime}-\pi_{j}^{\prime}\right|\right] .
\end{aligned}
$$

Step 8. Calculate the relative closeness coefficient to the intuitionistic ideal solution.

The relative closeness coefficient of an alternative $A_{i}$ with respect to the intuitionistic fuzzy positive-ideal solution $A^{*}$ is defined as follows:

$$
C_{i}^{*}=\frac{S_{i}^{-}}{S_{i}^{*}+S_{i}^{-}}
$$

where $0 \leq C_{i}^{*} \leq 1$.

Step 9. Calculate the result of $e_{k}$ from DEA and solution of $C_{i}^{*}$.

$$
e_{k}^{\prime}=e_{k} \otimes C_{i}^{*}
$$


Table 1: The DEA score.

\begin{tabular}{lc}
\hline DMU & Score \\
\hline 1 & 1 \\
2 & 0.951 \\
3 & 1 \\
4 & 1 \\
5 & 1 \\
6 & 0.869 \\
7 & 1 \\
8 & 1 \\
9 & 0.9200 \\
10 & 0.904 \\
11 & 0.834 \\
12 & 0.950 \\
13 & 1 \\
\hline
\end{tabular}

Table 2: linguistic term for rating decision makers.

\begin{tabular}{lc}
\hline Linguistic terms & IFNs \\
\hline Very important & $(0.85,0.10)$ \\
Important & $(0.50,0.20)$ \\
Medium & $(0.50,0.50)$ \\
Bad & $(0.35,0.60)$ \\
Very bad & $(0.10,0.85)$ \\
\hline
\end{tabular}

Step 10. Rank the alternatives.

After calculating the result of $e_{k^{\prime}}^{\prime}$ alternatives are ranked.

\section{Applying the Methodology: An Illustrative Problem}

The suggested model demonstrated via an example of a selected department, supported by a university. Thirteen departments have been considered in our evaluation. In our study, we employ a six-input evaluation criteria and four-output evaluation criteria.

Inputs: Number of Professor Doctors, Associated Professors, Assistant Professors, and Instructors; Budget of departments; and Number of credits.

Outputs: Number of alumni (undergraduates and graduate students), Evaluation of instructors, Number of academic congeries, and Number of academic papers (SCI-SSCIAHCI).

Step 1. Determine the result of $e_{k}$ from DEA in Table 1. In Table 1, seven units are efficient.

Step 2. Determine the weights of the decision makers: the degree of the decision makers on group decision, shown in Table 2, and Linguistic terms used for the ratings of the decision makers and criteria, as Table 3, respectively.

Step 3. Construct the aggregated intuitionistic fuzzy decision matrix based on the opinions of decision makers, the linguistic terms shown in Table 4. 
Table 3: The importance of decision makers and their weights.

\begin{tabular}{lccc}
\hline & DM1 & DM2 & DM3 \\
\hline Linguistic terms & Very important & Medium & Important \\
Weight & 0.385 & 0.307 & 0.307 \\
\hline
\end{tabular}

Table 4: Linguistic terms for rating the alternatives.

\begin{tabular}{lc}
\hline Linguistic terms & IFNs \\
\hline Extremely good (EG) & {$[1.00 ; 0.00 ; 0.00]$} \\
Very good (VG) & {$[0.85 ; 0,05 ; 0.10]$} \\
Good (G) & {$[0.70 ; 0.20 ; 0.10]$} \\
Medium bad (MB) & {$[0.50 ; 0.50 ; 0.00]$} \\
Bad (B) & {$[0.40 ; 0.50 ; 0.10]$} \\
Very bad (VB) & {$[0.25 ; 0.60 ; 0.15]$} \\
Extremely bad (EB) & {$[0.00,0.90,0.10]$} \\
\hline
\end{tabular}

The ratings given by the decision makers to 13 departments were shown in Table 5 .

The aggregated intuitionistic fuzzy decision matrix based on the aggregation of decison makers' opinion was constructed in Table 6.

Step 4. Determine the weights of criteria, the linguistic terms shown in Table 7, and the importance of the criteria which was rated by three decision makers shown in Table 8 .

Step 5. Construct the aggregated weighted Intuitionistic Fuzzy Decision Matrix shown in Table 9.

Finally calculate the relative closeness coefficient to the intuitionistic ideal solution shown in Table 10. Result of $e_{k}^{\prime}=e_{k} \otimes C_{i}^{*}$ and rank the alternatives shown in Table 11.

\section{Result and Discussion}

As presented in Table 10, the third column shows the scores of the thirteen departments. The result score is always the bigger the better. As visible in Table 10, department 3 has the largest score due to its highest efficiency and performance. Department 7 has the smallest score of the thirteen departments and is ranked in the last place. The relevant results can be seen in Table 10. Obviously, the best selection is department 3. Table 10 lists the results of both models, ordered according to DEA and IFS ranks. It is several units is there no compatibility between the two models: for example, departments 7 and 8, which are efficient in DEA but are ranked by DEA and IFS worse than the inefficient department 9 . Because it contains a vague perception of decision makers' opinions.

Although there is no perfect compatibility between DEA and DEA and IFS in the general case, empirically, we found many examples of complete match units. Applying the Mann-Whitney test to the above example, we found that the two methods are compatible with a $P$ value. 
Table 5: Ratings of the departments provided by three decision makers (DMs).

\begin{tabular}{|c|c|c|c|c|c|c|c|c|c|}
\hline DMU & Criteria & DM1 & DM2 & DM3 & DMU & Criteria & DM1 & DM2 & DM3 \\
\hline \multirow{6}{*}{ D1 } & $\mathrm{C} 1$ & VG & G & G & \multirow{6}{*}{ D8 } & $\mathrm{C} 1$ & VG & VG & VG \\
\hline & $\mathrm{C} 2$ & VG & VG & G & & $\mathrm{C} 2$ & VG & VG & G \\
\hline & $\mathrm{C} 3$ & G & MG & G & & $\mathrm{C} 3$ & MG & MG & MG \\
\hline & $\mathrm{C} 4$ & G & MG & VG & & C4 & MG & MG & MG \\
\hline & C5 & MG & MG & MG & & C5 & G & MG & G \\
\hline & C6 & VG & VG & VG & & $\mathrm{C} 6$ & VG & VG & VG \\
\hline \multirow{5}{*}{ D2 } & $\mathrm{C} 1$ & VG & VG & VG & \multirow{5}{*}{ D9 } & $\mathrm{C} 1$ & VG & G & VG \\
\hline & $\mathrm{C} 2$ & G & MG & G & & $\mathrm{C} 2$ & MG & G & MG \\
\hline & $\mathrm{C} 3$ & MG & G & VG & & $\mathrm{C} 3$ & G & G & G \\
\hline & C4 & G & G & G & & C4 & MG & MG & MG \\
\hline & C5 & MG & VG & G & & C5 & VG & G & G \\
\hline \multirow{7}{*}{ D3 } & C6 & VG & VG & VG & \multirow{7}{*}{ D10 } & C6 & VG & VG & VG \\
\hline & $\mathrm{C} 1$ & VG & VG & VG & & $\mathrm{C} 1$ & VG & VG & VG \\
\hline & $\mathrm{C} 2$ & VG & VG & VG & & $\mathrm{C} 2$ & G & VG & G \\
\hline & $\mathrm{C} 3$ & B & MG & MG & & $\mathrm{C} 3$ & G & G & G \\
\hline & $\mathrm{C} 4$ & VG & VG & VG & & $\mathrm{C} 4$ & G & MG & $\mathrm{MG}$ \\
\hline & C5 & G & VG & G & & C5 & G & G & G \\
\hline & C6 & G & VG & G & & $\mathrm{C} 6$ & VG & VG & VG \\
\hline \multirow{5}{*}{ D4 } & $\mathrm{C} 1$ & VG & MG & G & \multirow{5}{*}{ D11 } & $\mathrm{C} 1$ & G & VG & VG \\
\hline & $\mathrm{C} 2$ & G & G & VG & & $\mathrm{C} 2$ & VG & VG & VG \\
\hline & $\mathrm{C} 3$ & B & MG & MG & & $\mathrm{C} 3$ & VG & G & G \\
\hline & C4 & G & G & G & & C4 & G & G & G \\
\hline & C5 & B & B & MG & & C5 & MG & MG & MG \\
\hline \multirow{7}{*}{ D5 } & C6 & VG & VG & VG & \multirow{7}{*}{ D12 } & C6 & VG & VG & VG \\
\hline & $\mathrm{C} 1$ & VG & VG & VG & & $\mathrm{C} 1$ & G & VG & VG \\
\hline & $\mathrm{C} 2$ & VG & G & G & & $\mathrm{C} 2$ & G & G & G \\
\hline & C3 & G & G & G & & $\mathrm{C} 3$ & MG & MG & G \\
\hline & $\mathrm{C} 4$ & G & G & G & & $\mathrm{C} 4$ & $\mathrm{G}$ & G & G \\
\hline & C5 & G & MG & MG & & C5 & MG & MG & $\mathrm{MG}$ \\
\hline & C6 & VG & VG & VG & & C6 & VG & $\mathrm{G}$ & VG \\
\hline \multirow{6}{*}{ D6 } & $\mathrm{C} 1$ & VG & VG & VG & \multirow{6}{*}{ D13 } & $\mathrm{C} 1$ & VG & VG & G \\
\hline & $\mathrm{C} 2$ & VG & VG & VG & & $\mathrm{C} 2$ & VG & VG & VG \\
\hline & C3 & B & MG & MG & & $\mathrm{C} 3$ & VG & G & G \\
\hline & C4 & G & G & VG & & C4 & G & G & G \\
\hline & C5 & B & B & MG & & C5 & MG & MG & $\mathrm{MG}$ \\
\hline & C6 & G & G & MG & & C6 & G & G & G \\
\hline \multirow{6}{*}{ D7 } & $\mathrm{C} 1$ & VG & VG & VG & & & & & \\
\hline & $\mathrm{C} 2$ & MG & MG & MG & & & & & \\
\hline & C3 & MG & MG & MG & & & & & \\
\hline & C4 & G & G & MG & & & & & \\
\hline & C5 & G & G & G & & & & & \\
\hline & C6 & VG & VG & VG & & & & & \\
\hline
\end{tabular}


Table 6: Aggregate intuitionistic fuzzy decision matrix.

\begin{tabular}{|c|c|c|c|c|c|}
\hline$\overline{\mathrm{DMU}}$ & Criteria & & DMU & Criteria & \\
\hline \multirow{6}{*}{ D1 } & $\mathrm{C} 1$ & $(0.770,0.118,0.112)$ & \multirow{6}{*}{ D8 } & $\mathrm{C} 1$ & $(0.770,0.118,0.112)$ \\
\hline & $\mathrm{C} 2$ & $(0.814,0.077,0.109)$ & & $\mathrm{C} 2$ & $(0.831,0.077,0.093)$ \\
\hline & $\mathrm{C} 3$ & $(0.649,0.265,0.086)$ & & C3 & $(0.500,0.500,0.000)$ \\
\hline & $\mathrm{C} 4$ & $(0.716,0.173,0.111)$ & & C4 & $(0.500,0.500,0.000)$ \\
\hline & $\mathrm{C} 5$ & $(0.500,0.285,0.215)$ & & $\mathrm{C} 5$ & $(0.649,0.265,0.086)$ \\
\hline & C6 & $(0.850,0.050,0.100)$ & & C6 & $(0.770,0.118,0.112)$ \\
\hline \multirow{6}{*}{ D2 } & $\mathrm{C} 1$ & $(0.850,0.050,0.100)$ & \multirow{6}{*}{ D9 } & $\mathrm{C} 1$ & $(0.814,0.068,0.118)$ \\
\hline & $\mathrm{C} 2$ & $(0.649,0.265,0.086)$ & & $\mathrm{C} 2$ & $(0.572,0.378,0.050)$ \\
\hline & $\mathrm{C} 3$ & $(0.704,0.186,0.109)$ & & $\mathrm{C} 3$ & $(0.700,0.200,0.100)$ \\
\hline & $\mathrm{C} 4$ & $(0.700,0.200,0.100)$ & & $\mathrm{C} 4$ & $(0.500,0.500,0.000)$ \\
\hline & C5 & $(0.704,0.186,0.109)$ & & C5 & $(0.770,0.118,0.112)$ \\
\hline & C6 & $(0.850,0.050,0.100)$ & & $\mathrm{C} 6$ & $(0.850,0.051,0.100)$ \\
\hline \multirow{6}{*}{ D3 } & $\mathrm{C} 1$ & $(0.850,0.050,0.100)$ & \multirow{6}{*}{ D10 } & $\mathrm{C} 1$ & $(0.850,0.050,0.100)$ \\
\hline & $\mathrm{C} 2$ & $(0.850,0.050,0.100)$ & & $\mathrm{C} 2$ & $(0.757,0.131,0.112)$ \\
\hline & $\mathrm{C} 3$ & $(0.463,0.500,0.036)$ & & $\mathrm{C} 3$ & $(0.700,0.200,0.100)$ \\
\hline & $\mathrm{C} 4$ & $(0.850,0.500,0.100)$ & & $\mathrm{C} 4$ & $(0.589,0.352,0.060)$ \\
\hline & C5 & $(0.757,0.131,0.112)$ & & C5 & $(0.700,0.200,0.100)$ \\
\hline & C6 & $(0.850,0.050,0.100)$ & & C6 & $(0.850,0.050,0.100)$ \\
\hline \multirow{6}{*}{ D4 } & $\mathrm{C} 1$ & $(0.731,0.156,0.114)$ & \multirow{6}{*}{ D11 } & $\mathrm{C} 1$ & $(0.804,0.086,0.111)$ \\
\hline & $\mathrm{C} 2$ & $(0.757,0.139,0.112)$ & & $\mathrm{C} 2$ & $(0.850,0.051,0.100)$ \\
\hline & $\mathrm{C} 3$ & $(0.463,0.500,0.037)$ & & $\mathrm{C} 3$ & $(0.770,0.118,0.112)$ \\
\hline & $\mathrm{C} 4$ & $(0.700,0.200,0.100)$ & & $\mathrm{C} 4$ & $(0.700,0.200,0.100)$ \\
\hline & C5 & $(0.432,0.500,0.067)$ & & C5 & $(0.500,0.500,0.000)$ \\
\hline & C6 & $(0.850,0.050,0.100)$ & & C6 & $(0.850,0.050,0.100)$ \\
\hline \multirow{6}{*}{ D5 } & $\mathrm{C} 1$ & $(0.850,0.050,0.100)$ & \multirow{6}{*}{ D12 } & $\mathrm{C} 1$ & $(0.804,0.086,0.111)$ \\
\hline & $\mathrm{C} 2$ & $(0.770,0.118,0.112)$ & & $\mathrm{C} 2$ & $(0.700,0.200,0.100)$ \\
\hline & C3 & $(0.700,0.200,0.100)$ & & C3 & $(0.572,0.378,0.050)$ \\
\hline & $\mathrm{C} 4$ & $(0.700,0.200,0.100)$ & & C4 & $(0.700,0.200,0.100)$ \\
\hline & $\mathrm{C} 5$ & $(0.589,0.352,0.060)$ & & $\mathrm{C} 5$ & $(0.500,0.500,0.000)$ \\
\hline & C6 & $(0.850,0.050,0.100)$ & & C6 & $(0.814,0.068,0.118)$ \\
\hline \multirow{6}{*}{ D6 } & $\mathrm{C} 1$ & $(0.850,0.050,0.100)$ & \multirow{6}{*}{ D13 } & $\mathrm{C} 1$ & $(0.814,0.078,0.109)$ \\
\hline & $\mathrm{C} 2$ & $(0.850,0.050,0.100)$ & & $\mathrm{C} 2$ & $(0.850,0.051,0.100)$ \\
\hline & C3 & $(0.463,0.500,0.036)$ & & $\mathrm{C} 3$ & $(0.770,0.118,0.112)$ \\
\hline & C4 & $(0.716,0.131,0.153)$ & & $\mathrm{C} 4$ & $(0.700,0.200,0.100)$ \\
\hline & C5 & $(0.432,0.500,0.067)$ & & C5 & $(0.500,0.500,0.000)$ \\
\hline & C6 & $(0.649,0.265,0.086)$ & & C6 & $(0.700,0.200,0.100)$ \\
\hline \multirow{6}{*}{ D7 } & $\mathrm{C} 1$ & $(0.770,0.118,0.112)$ & & & \\
\hline & $\mathrm{C} 2$ & $(0.500,0.500,0.000)$ & & & \\
\hline & $\mathrm{C} 3$ & $(0.500,0.500,0.000)$ & & & \\
\hline & $\mathrm{C} 4$ & $(0.649,0.265,0.086)$ & & & \\
\hline & $\mathrm{C} 5$ & $(0.700,0.200,0.100)$ & & & \\
\hline & C6 & $(0.770,0.118,0.112)$ & & & \\
\hline
\end{tabular}

Table 7: Linguistic terms for rating the importance of criteria.

\begin{tabular}{lc}
\hline Linguistic terms & IFNs \\
\hline Very good (VG) & {$[0.90 ; 0,00]$} \\
Good $(G)$ & {$[0.80 ; 0.10]$} \\
Medium bad (MB) & {$[0.70 ; 0.20]$} \\
Bad $(B)$ & {$[0.50 ; 0.50]$} \\
Very bad (VB) & {$[0.30 ; 0.50]$} \\
Extremely bad (EB) & {$[0.20 ; 0.70]$} \\
\hline
\end{tabular}


Table 8: Importance weight of the criteria.

\begin{tabular}{lccccccc}
\hline Criteria & DM1 & DM2 & DM3 & Criteria & DM1 & DM2 & DM3 \\
\hline C1 & G & MB & MB & C4 & G & G & MB \\
C2 & VG & VG & VG & D5 & G & MB & B \\
C3 & B & G & MB & C6 & VG & VG & VG \\
\hline
\end{tabular}

Table 9: Aggregated weighted intuitionistic fuzzy decision matrix.

\begin{tabular}{|c|c|c|c|c|c|}
\hline Alternative & Criteria & & Alternative & Criteria & \\
\hline \multirow{6}{*}{ D1 } & $\mathrm{C} 1$ & $(0.572,0.253,0.175)$ & \multirow{6}{*}{ D8 } & $\mathrm{C} 1$ & $(0.572,0.341,0.087)$ \\
\hline & $\mathrm{C} 2$ & $(0.732,0.077,0.191)$ & & $\mathrm{C} 2$ & $(0.744,0.077,0.176)$ \\
\hline & $\mathrm{C} 3$ & $(0.439,0.439,0.122)$ & & $\mathrm{C} 3$ & $(0.338,0.618,0.044)$ \\
\hline & $\mathrm{C} 4$ & $(0.553,0.276,0.171)$ & & $\mathrm{C} 4$ & $(0.386,0.562,0.052)$ \\
\hline & C5 & $(0.349,0.430,0.221)$ & & C5 & $(0.454,0.415,0.131)$ \\
\hline & C6 & $(0.764,0.050,0.186)$ & & C6 & $(0.692,0.118,0.190)$ \\
\hline \multirow{6}{*}{ D2 } & $\mathrm{C} 1$ & $(0.631,0.195,0.174)$ & \multirow{6}{*}{ D9 } & $\mathrm{C} 1$ & $(0.605,0.210,0.185)$ \\
\hline & $\mathrm{C} 2$ & $(0.583,0.265,0.152)$ & & $\mathrm{C} 2$ & $(0.514,0.378,0.108)$ \\
\hline & $\mathrm{C} 3$ & $(0.477,0.378,0.145)$ & & $\mathrm{C} 3$ & $(0.474,0.389,0.137)$ \\
\hline & $\mathrm{C} 4$ & $(0.541,0.299,0.160)$ & & $\mathrm{C} 4$ & $(0.386,0.562,0.052)$ \\
\hline & C5 & $(0.492,0.351,0.157)$ & & C5 & $(0.538,0.297,0.165)$ \\
\hline & C6 & $(0.764,0.050,0.186)$ & & C6 & $(0.764,0.051,0.185)$ \\
\hline \multirow{6}{*}{ D3 } & $\mathrm{C} 1$ & $(0.631,0.195,0.174)$ & \multirow{6}{*}{ D10 } & $\mathrm{C} 1$ & $(0.631,0.197,0.172)$ \\
\hline & $\mathrm{C} 2$ & $(0.764,0.050,0.186)$ & & $\mathrm{C} 2$ & $(0.681,0.131,0.188)$ \\
\hline & $\mathrm{C} 3$ & $(0.314,0.618,0.068)$ & & $\mathrm{C} 3$ & $(0.474,0.389,0.137)$ \\
\hline & $\mathrm{C} 4$ & $(0.657,0.168,0.175)$ & & $\mathrm{C} 4$ & $(0.455,0.432,0.113)$ \\
\hline & $\mathrm{C} 5$ & $(0.529,0.307,0.164)$ & & C5 & $(0.489,0.363,0.148)$ \\
\hline & C6 & $(0.764,0.050,0.186)$ & & C6 & $(0.764,0.050,0.186)$ \\
\hline \multirow{6}{*}{$\mathrm{D} 4$} & $\mathrm{C} 1$ & $(0.543,0.285,0.172)$ & \multirow{6}{*}{ D11 } & $\mathrm{C} 1$ & $(0.597,0.255,0.178)$ \\
\hline & $\mathrm{C} 2$ & $(0.681,0.139,0.180)$ & & $\mathrm{C} 2$ & $(0.764,0.051,0.185)$ \\
\hline & $\mathrm{C} 3$ & $(0.314,0.618,0.068)$ & & $\mathrm{C} 3$ & $(0.521,0.326,0.153)$ \\
\hline & $\mathrm{C} 4$ & $(0.541,0.299,0.160)$ & & $\mathrm{C} 4$ & $(0.541,0.299,0.160)$ \\
\hline & C5 & $(0.302,0.602,0.096)$ & & C5 & $(0.349,0.602,0.049)$ \\
\hline & C6 & $(0.764,0.050,0.186)$ & & C6 & $(0.764,0.050,0.186)$ \\
\hline \multirow{6}{*}{ D5 } & $\mathrm{C} 1$ & $(0.631,0.367,0.002)$ & \multirow{6}{*}{ D12 } & $\mathrm{C} 1$ & $(0.597,0.225,0.178)$ \\
\hline & $\mathrm{C} 2$ & $(0.692,0.118,0.190)$ & & $\mathrm{C} 2$ & $(0.629,0.200,0.171)$ \\
\hline & $\mathrm{C} 3$ & $(0.474,0.389,0.137)$ & & $\mathrm{C} 3$ & $(0.387,0.524,0.089)$ \\
\hline & $\mathrm{C} 4$ & $(0.541,0.299,0.160)$ & & $\mathrm{C} 4$ & $(0.541,0.299,0.160)$ \\
\hline & C5 & $(0.412,0.483,0.105)$ & & C5 & $(0.349,0.602,0.049)$ \\
\hline & C6 & $(0.764,0.050,0.186)$ & & C6 & $(0.732,0.068,0.200)$ \\
\hline \multirow{6}{*}{ D6 } & $\mathrm{C} 1$ & $(0.631,0.195,0.174)$ & \multirow{12}{*}{ D13 } & $\mathrm{C} 1$ & $(0.605,0.218,0.177)$ \\
\hline & $\mathrm{C} 2$ & $(0.764,0.050,0.186)$ & & $\mathrm{C} 2$ & $(0.764,0.051,0.186)$ \\
\hline & $\mathrm{C} 3$ & $(0.314,0.618,0.068)$ & & $\mathrm{C} 3$ & $(0.521,0.326,0.153)$ \\
\hline & $\mathrm{C} 4$ & $(0.553,0.239,0.208)$ & & $\mathrm{C} 4$ & $(0.541,0.299,0.160)$ \\
\hline & $\mathrm{C} 5$ & $(0.302,0.602,0.096)$ & & $\mathrm{C} 5$ & $(0.349,0.602,0.049)$ \\
\hline & C6 & $(0.583,0.265,0.152)$ & & C6 & $(0.629,0.200,0.171)$ \\
\hline \multirow{6}{*}{ D7 } & $\mathrm{C} 1$ & $(0.572,0.253,0.175)$ & & & \\
\hline & $\mathrm{C} 2$ & $(0.449,0.500,0.051)$ & & & \\
\hline & $\mathrm{C} 3$ & $(0.338,0.618,0.044)$ & & & \\
\hline & $\mathrm{C} 4$ & $(0.501,0.356,0.143)$ & & & \\
\hline & C5 & $(0.489,0.363,0.148)$ & & & \\
\hline & C6 & $(0.692,0.118,0.190)$ & & & \\
\hline
\end{tabular}


Table 10: Separation measurement and the relative closeness coefficient of each department.

\begin{tabular}{lccc}
\hline DMU & $S^{*}$ & $S^{-}$ & $C_{i}^{*}$ \\
\hline D1 & 0.562 & 1.518 & 0.730 \\
D2 & 0.513 & 1.350 & 0.750 \\
D3 & 0.363 & 1.500 & 0.805 \\
D4 & 0.968 & 0.895 & 0.480 \\
D5 & 0.685 & 1.322 & 0.659 \\
D6 & 0.976 & 0.919 & 0.485 \\
D7 & 1.563 & 0.654 & 0.295 \\
D8 & 1.110 & 0.810 & 0.422 \\
D9 & 0.849 & 1.003 & 0.542 \\
D10 & 0.539 & 1.326 & 0.711 \\
D11 & 0.531 & 1.383 & 0.723 \\
D12 & 0.911 & 1.017 & 0.527 \\
D13 & 0.674 & 1.240 & 0.648 \\
\hline
\end{tabular}

Table 11: The DEA and intuitionistic fuzzy TOPSIS ranking score.

\begin{tabular}{lcc}
\hline DMU & DEA & DEA-IFS \\
\hline D1 & 1 & 0.730 \\
D2 & 0.951 & 0.689 \\
D3 & $\mathbf{1}$ & $\mathbf{0 . 8 0 5}$ \\
D4 & 1 & 0.480 \\
D5 & 1 & 0.659 \\
D6 & 0.869 & 0.421 \\
D7 & 1 & $\mathbf{0 . 2 9 5}$ \\
D8 & 1 & 0.422 \\
D9 & 0.9200 & 0.499 \\
D10 & 0.904 & 0.642 \\
D11 & 0.834 & 0.603 \\
D12 & 0.950 & 0.500 \\
D13 & 1 & 0.648 \\
\hline
\end{tabular}

\section{Conclusion}

In this paper, we have demonstrated a simple and easy-to-use method for department comparison via DEA. Furthermore, we integrated IFS in DEA to generate a more feasible DEA result. Various types of data were adopted in DEA without any modification of the DEA formula. We have presented an effective model for rank scaling of the units with multiple inputs and multiple outputs using both DEA and IFS.

The DEA and IFS method combines the best of both models by avoiding the pitfalls of each. IFS are designed for subjective evaluation of a set of alternatives based on multiple criteria organized in a hierarchical structure. The IFS is a suitable way to deal with uncertainty. In the evaluation process, the ratings of each alternative, which were given with Intuitionistic fuzzy information, were represented as IFNs. The IFWA operator was used to aggregate the rating of decision makers. The intuitionistic fuzzy TOPSIS method is a suitable method for MCDM because it contains a vague perception of decision makers' opinions. It is important to note that DEA and IFS do not replace DEA, but rather, it provides further 
analysis of DEA to full ranking the units, within utilized to aggregated individual opinions of decision makers for rating the importance of criteria and alternatives. Therefore, in the future, DEA and IFS models can be used to problems such as health systems, project selection, and many other areas.

\section{References}

[1] A. Charnes, W. W. Cooper, and E. Rhodes, "Measuring the efficiency of decision making units," European Journal of Operational Research, vol. 2, no. 6, pp. 429-444, 1978.

[2] B. Golany, "An interactive MOLP procedure for the extension of data envelopment analysis to effectiveness analysis," Journal of the Operational Research Society, vol. 39, no. 8, pp. 725-734, 1988.

[3] J. S. H. Kornbluth, "Analysing policy effectiveness using cone restricted data envelopment analysis," Journal of the Operational Research Society, vol. 42, no. 12, pp. 1097-1104, 1991.

[4] B. Golany and Y. A. Roll, "Incorporating standards via data envelopment analysis," in Data Envelopment Analysis: Theory, Methodology and Applications, A. Charnes, W. W. Cooper, A. Y. Lewin, and L. M. Seiford, Eds., Kluwer Academic Publishers, Norwell, Mass, USA, 1994.

[5] M. Halme, T. Joro, P. Korhonen, S. Salo, and J. Wallenius, "A value efficiency approach to incorporating preference information in data envelopment analysis," Management Science, vol. 45, no. 1, pp. 103-115, 1999.

[6] N. Adler, L. Friedman, and Z. Sinuany-Stern, "Review of ranking methods in the data envelopment analysis context," European Journal of Operational Research, vol. 140, no. 2, pp. 249-265, 2002.

[7] W. W. Cooper, L. M. Seiford, and J. Zhu, Eds., Handbook on Data Envelopment Analysis, International Series in Operations Research \& Management Science, 71, Kluwer Academic Publishers, Boston, Mass, USA, 2004.

[8] W. D. Cook and M. Kress, "A data envelopment model for aggregating preference ranking," Management Science, vol. 36, no. 11, pp. 1302-1310, 1990.

[9] W. D. Cook, M. Kress, and L. M. Seiford, "Prioritization models for frontier decision making units in DEA," European Journal of Operational Research, vol. 59, no. 2, pp. 319-323, 1992.

[10] R. H. Green, J. R. Doyle, and W. D. Cook, "Preference voting and project ranking using DEA and cross-evaluation," European Journal of Operational Research, vol. 90, no. 3, pp. 461-472, 1996.

[11] M. Norman and B. Stoker, Data Envelopment Analysis: The Assessment of Performance, John Wiley \& Sons, New York, NY, USA, 1991.

[12] J. A. Ganley and J. S. Cubbin, Public Sector Efficiency Measurement: Applications of Data Envelopment Analysis, Elsevier Science Publishers, 1992.

[13] Z. Sinuany-Stern, A. Mehrez, and Y. Hadad, “An AHP/DEA methodology for ranking decision making units," International Transactions in Operational Research, vol. 7, no. 2, pp. 109-124, 2000.

[14] L. Friedman and Z. Sinuany-Stern, "Scaling units via the canonical correlation analysis in the DEA context," European Journal of Operational Research, vol. 100, no. 3, pp. 629-637, 1997.

[15] Z. Sinuany-Stern and L. Friedman, "DEA and the discriminant analysis of ratios for ranking units," European Journal of Operational Research, vol. 111, no. 3, pp. 470-478, 1998.

[16] M. Oral, O. Kettani, and P. Lang, "A methodology for collective evaluation and selection of industrial R\&D projects," Management Science, vol. 7, no. 37, pp. 871-883, 1991.

[17] B. D. Rouyendegh and S. Erol, “The DEA-FUZZY ANP Department Ranking Model Applied in Iran Amirkabir University," Acta Polytechnica Hungarica, vol. 7, no. 4, pp. 103-114, 2010.

[18] K. T. Atanassov, "Intuitionistic fuzzy sets," Fuzzy Sets and Systems, vol. 20, no. 1, pp. 87-96, 1986.

[19] S. K. De, R. Biswas, and A. R. Roy, "An application of intuitionistic fuzzy sets in medical diagnosis," Fuzzy Sets and Systems, vol. 117, no. 2, pp. 209-213, 2001.

[20] E. Szmidt and J. Kacprzyk, "Distances between intuitionistic fuzzy sets," Fuzzy Sets and Systems, vol. 114 , no. 3, pp. 505-518, 2000.

[21] E. Szmidt and J. Kacprzyk, "Intuitionistic fuzzy sets in some medical applications," in Proceedings of the International Conference, 7th Fuzzy Days on Computational Intelligence, Theory and Applications, vol. 2206 of Lecture Notes in Computer Science, pp. 148-151, Dortmund, Germany, October 2001.

[22] K. Atanassov, G. Pasi, and R. Yager, "Intuitionistic fuzzy interpretations of multi-criteria multi-person and multi-measurement tool decision making," International Journal of Systems Science, vol. 36, no. 14, pp. 859-868, 2005. 
[23] D. H. Hong and C. H. Choi, "Multicriteria fuzzy decision-making problems based on vague set theory," Fuzzy Sets and Systems, vol. 114, no. 1, pp. 103-113, 2000.

[24] H. W. Liu and G. J. Wang, "Multi-criteria decision-making methods based on intuitionistic fuzzy sets," European Journal of Operational Research, vol. 179, no. 1, pp. 220-233, 2007.

[25] E. Szmidt and J. Kacprzyk, "Using intuitionistic fuzzy sets in group decision making," Control and Cybernetics, vol. 31, no. 4, pp. 1037-1053, 2002.

[26] E. Szmidt and J. Kacprzyk, "A consensus-reaching process under intuitionistic fuzzy preference relations," International Journal of Intelligent Systems, vol. 18, no. 7, pp. 837-852, 2003.

[27] P. Wang, "QoS-aware web services selection with intuitionistic fuzzy set under consumer's vague perception," Expert Systems with Applications, vol. 36, no. 3, pp. 4460-4466, 2009.

[28] Z. Xu, "Intuitionistic preference relations and their application in group decision making," Information Sciences, vol. 177, no. 11, pp. 2363-2379, 2007.

[29] Z. Xu, "Some similarity measures of intuitionistic fuzzy sets and their applications to multiple attribute decision making," Fuzzy Optimization and Decision Making, vol. 6, no. 2, pp. 109-121, 2007.

[30] Z. S. Xu, "Models for multiple attribute decision making with intuitionistic fuzzy information," International Journal of Uncertainty, Fuzziness and Knowlege-Based Systems, vol. 15, no. 3, pp. 285-297, 2007.

[31] Z. Xu and R. R. Yager, "Dynamic intuitionistic fuzzy multi-attribute decision making," International Journal of Approximate Reasoning, vol. 48, no. 1, pp. 246-262, 2008.

[32] W. L. Hung and M. S. Yang, "Similarity measures of intuitionistic fuzzy sets based on Hausdorff distance," Pattern Recognition Letters, vol. 25, no. 14, pp. 1603-1611, 2004.

[33] D. F. Li and C. T. Cheng, "New similarity measures of intuitionistic fuzzy sets and application to pattern recognitions," Pattern Recognition Letters, vol. 23, no. 1-3, pp. 221-225, 2002.

[34] Z. Liang and P. Shi, "Similarity measures on intuitionistic fuzzy sets," Pattern Recognition Letters, vol. 24, no. 15, pp. 2687-2693, 2003.

[35] I. K. Vlachos and G. D. Sergiadis, "Intuitionistic fuzzy information-applications to pattern recognition," Pattern Recognition Letters, vol. 28, no. 2, pp. 197-206, 2007.

[36] W. Wang and X. Xin, "Distance measure between intuitionistic fuzzy sets," Pattern Recognition Letters, vol. 26, no. 13, pp. 2063-2069, 2005.

[37] C. Zhang and H. Fu, "Similarity measures on three kinds of fuzzy sets," Pattern Recognition Letters, vol. 27, no. 12, pp. 1307-1317, 2006.

[38] F. E. Boran, S. Genç, M. Kurt, and D. Akay, "A multi-criteria intuitionistic fuzzy group decision making for supplier selection with TOPSIS method," Expert Systems with Applications, vol. 36, no. 8, pp. 11363-11368, 2009.

[39] F. E. Boran, S. Genã, and D. Akay, "Personnel selection based on intuitionistic fuzzy sets," Human Factors and Ergonomics in Manufacturing, vol. 21, no. 5, pp. 493-503, 2011.

[40] F. E. Boran, "An integrated intuitionistic fuzzy multi criteria decision making method for facility location selection," Mathematical and Computational Applications, vol. 16, no. 2, pp. 487-496, 2011.

[41] F. E. Boran, K. Boran, and T. Menlik, "The evaluation of renewable energy technologies for electricity generation in Turkey using intuitionistic fuzzy TOPSIS," Energy Sources Part B, vol. 7, no. 1, pp. 81-90, 2012.

[42] A. Bessent and W. Bessent, "Evaluation of educational program proposals by means of DEA," Educational Administration Quarterly, vol. 19, no. 2, pp. 82-107, 1983.

[43] C. Tomkins and R. Green, "An experiment in the use of data envelopment analysis for evaluating the effciency of UK university departments of accounting," Financial Accountability \& Management, vol. 4, no. 2, pp. 147-164, 1988.

[44] J. E. Beasley, “Comparing university departments," Omega, vol. 18, no. 2, pp. 171-183, 1990.

[45] J. Johnes and G. Johnes, "Research funding and performance in U.K. University Departments of Economics: a frontier analysis," Economics of Education Review, vol. 14, no. 3, pp. 301-314, 1995.

[46] Z. Sinuany-Stern, A. Mehrez, and A. Barboy, "Academic departments efficiency via DEA," Computers and Operations Research, vol. 21, no. 5, pp. 543-556, 1994.

[47] K. H. Leitner, J. Prikoszovits, M. Schaffhauser-Linzatti, R. Stowasser, and K. Wagner, "The impact of size and specialisation on universities' department performance: a DEA analysis applied to Austrian universities," Higher Education, vol. 53, no. 4, pp. 517-538, 2007.

[48] M. M. Rayeni, G. Vardanyan, and F. H. Saljooghi, "The measurement of productivity growth in the academic departments using malmquist productivity index," Journal of Applied Sciences, vol. 10, no. 22, pp. 2875-2880, 2010. 
[49] Z. Xu, "Intuitionistic fuzzy aggregation operators," IEEE Transactions on Fuzzy Systems, vol. 15, no. 6, pp. 1179-1187, 2007.

[50] K. T. Atanassov, Intuitionistic Fuzzy Sets. Theory and Applications, vol. 35 of Studies in Fuzziness and Soft Computing, Physica, Heidelberg, Germany, 1999.

[51] E. Szmidt and J. Kacprzyk, "A similarity measure for intuitionistic fuzzy sets and its application in supporting medical diagnostic reasoning," in Proceedings of the 7th International Conference on Artificial Intelligence and Soft Computing (ICAISC'04), vol. 3070 of Lecture Notes in Computer Science, pp. 388-393, June 2004.

[52] P. Grzegorzewski, "Distances between intuitionistic fuzzy sets and/or interval-valued fuzzy sets based on the Hausdorff metric," Fuzzy Sets and Systems, vol. 148, no. 2, pp. 319-328, 2004. 


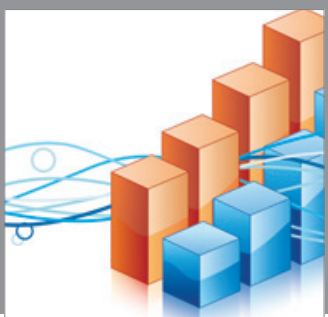

Advances in

Operations Research

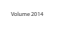

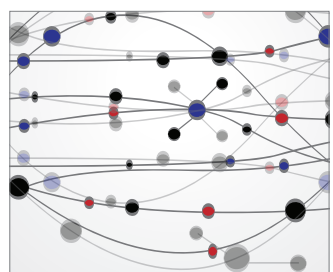

\section{The Scientific} World Journal
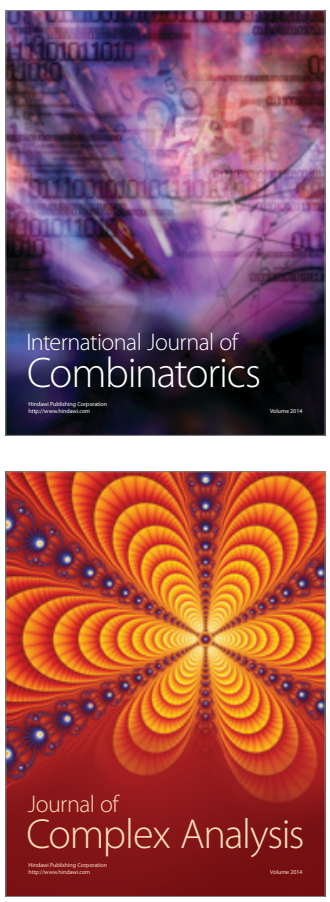

International Journal of

Mathematics and

Mathematical

Sciences
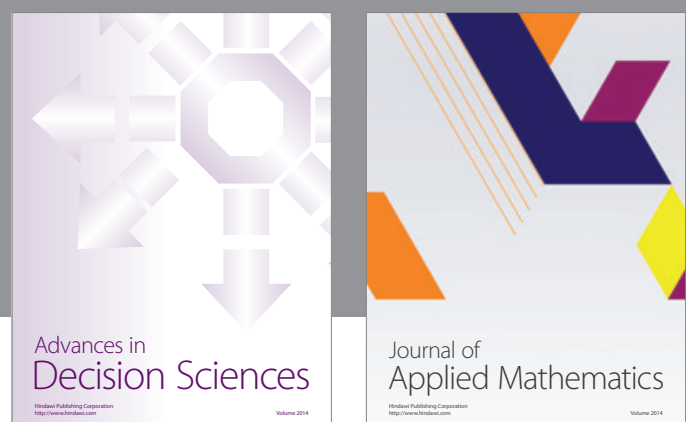

Journal of

Applied Mathematics


Submit your manuscripts at http://www.hindawi.com
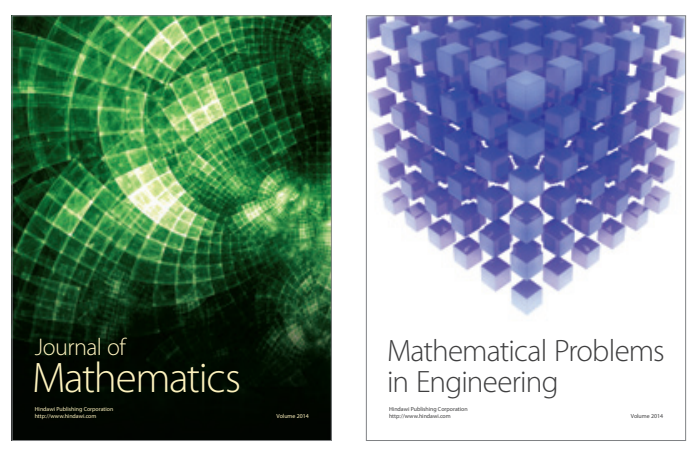

Mathematical Problems in Engineering


Journal of

Function Spaces
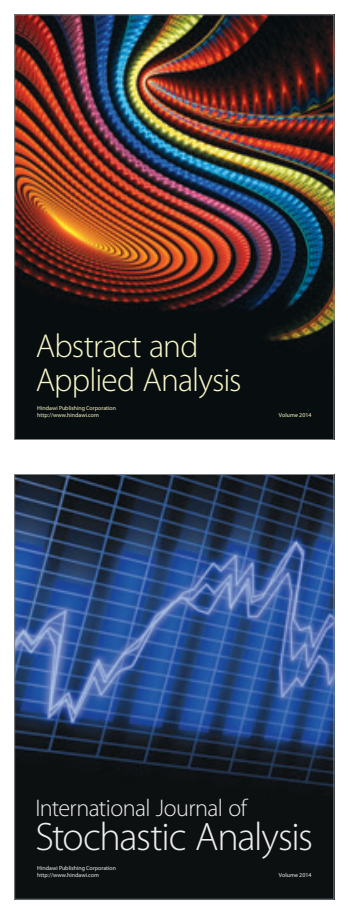

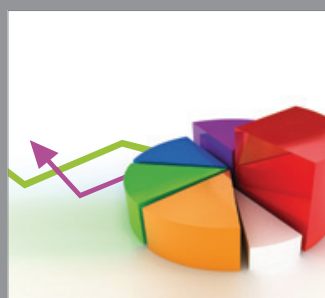

ournal of

Probability and Statistics

Promensencen
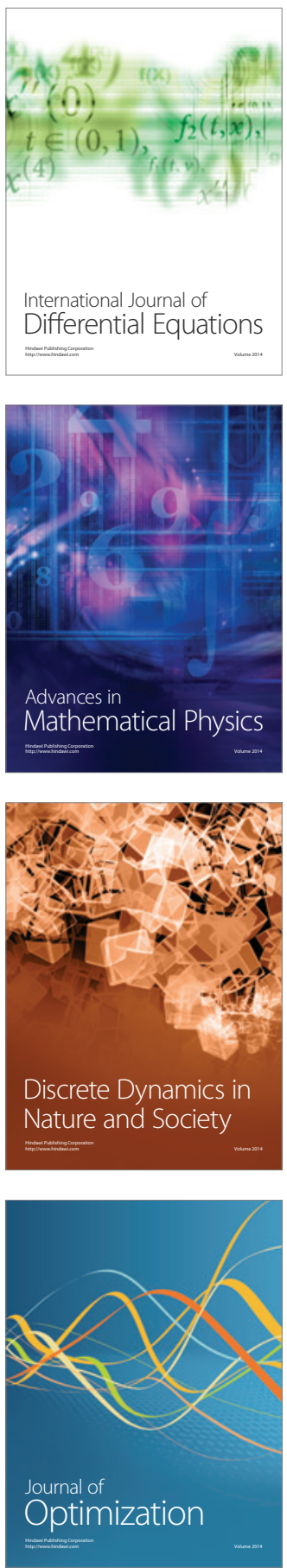